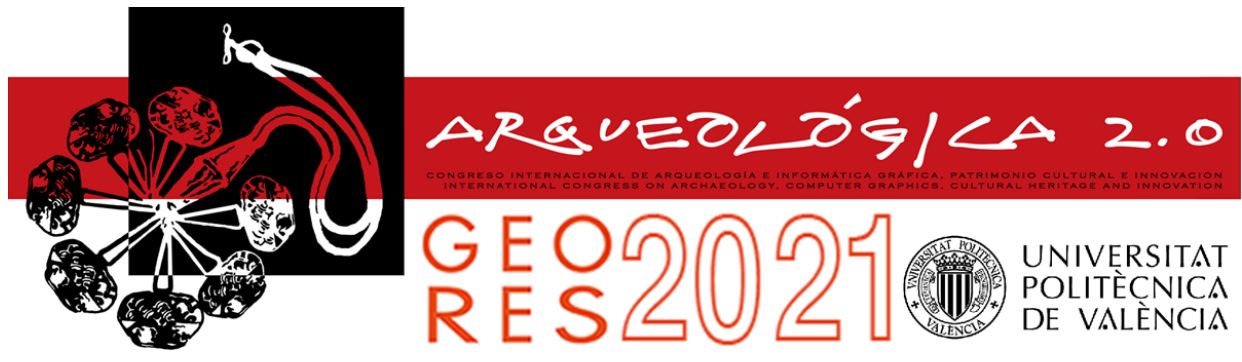

\title{
THE RECONSTRUCTION OF A DYNAMIC INVENTORY MODEL TOWARD SHARED HBIM LIBRARIES FOR VAULTED SYSTEMS
}

\author{
Anna Turrina*, Dario Attico \\ Department of Architecture, Built Environment and Construction (DABC), Polytechnic of Milan, Via Ponzio 31, 20133 Milan, Italy. \\ anna.turrina@polimi.it; dario.attico@polimi.it
}

\section{Abstract: THE RECONSTRUCTION OF A DYNAMIC INVENTORY MODEL TOWARD SHARED HBIM LIBRARIES FOR VAULTED SYSTEMS}

The complexity and variety of solutions in the domain of cultural heritage are the results of a heterogeneous network of social and historical factors generating them. Each individual architectural object, including not only notorious typologies but little-known construction systems such as brick vaults, are generated by a specific social and physical framework. The richness of vaulted systems stresses the need for an in-depth investigation supported by informative models connected in a single geospatial platform. The paper describes a methodological workflow starting from an abacus of vaults, based on different Levels of Detail and Information, to populate a geo-spatial database. Focusing on the acquisition of an open and shared database of historical elements, the definition of an HBIM targeted Library, integrating different types of data in one dynamic model, requires the management of different Levels of Detail and guidelines to establish a correct hierarchy of information. The proposed study can be considered a modern approach to the traditional practice of Répertoires, to set up a methodology that could be applied indifferently and widely, regardless of how the model is built. The diverse vaulted systems of Palazzo Magio Grasselli provide the possibility to build an inventory model as a result of multiple informative models coming from different geographical backgrounds to solve critical issues such as data loss and to enhance knowledge dissemination.

Keywords: HBIM, vault, LOD, digitization, database, cultural heritage

\section{Introduction}

The study of cultural heritage still moves its steps among unsolved issues related to the complexity and variety of solutions in time and space. The presence of a large stock of historical buildings, with variable connotations in different Italian regions, makes it necessary to adopt a systematic approach to gather the information.

The suggested study can be considered a modern approach to the traditional practice of Repertoires, to set up a methodology that could be applied indifferently and widely, regardless of how the model is built. Each individual architectural object, including not only notorious typologies but little-known construction systems such as brick vaults, are generated by a specific social and physical framework. The richness of vaulted systems stresses the need for an in-depth investigation supported by informative models grouped in a single geo-spatial database to allow a geographical reconstruction.

\section{Following the logic of a modern Répertoire}

In order to create a database aimed to organize the construction elements, an important reference can be found in the concept of Répertoire formed within the French culture.

Towards the end of the twentieth century, the topic of vaulted systems returned to the center of architectural culture and became particularly interesting among scholars and historians after an eclipse of almost a hundred years (Brumana et al., 2018a).

Important cases of stereotomy, made between the sixteenth and nineteenth centuries, that is from the late Gothic to the Baroque époque, have been subject of studies to reconstruct a new historical perspective.

This phenomenon affected Europe as a whole, in France thanks Jean Marie Pérouse de Montclos (2000) in 1964 it took up the idea of inventory by recording a significant number of cases of stereotomic treatment, attributing a typological vocabulary to each individual example. We can therefore speak of a revival of the French répertoires and a reimagining of the treatise of De l'Orme, where the technical vocabulary of architecture is associated with a lexicon through the illustration of the different cases.

In the following years, other studies were performed less systematically in Spain (Palacios, 1990), England (Willis, 1842 ) and Germany. In Italy, treaties - with the exception

‘Corresponding Author: Anna Turrina, anna.turrina@polimi.it 
of Guarini (Piccoli, 2001) - were often elementary and repetitive. From the seventeenth century, there is a direct reference to the notions of French literature. At the same time, the presence of the recovery manuals of the individual cities began to spread, but with a limit, that is, the treatment of typically local customs and techniques. This fragmented framework makes it difficult to recognize a way of building linked to a specific region, because the same skilled workers often operate by moving geographically from one border to another. If Piedmont is known for offering a large number of examples of brick vaults, it is not possible to attribute authorship to the region. The famous thin vaults, for example, are often traced back to Piedmonts architecture for their massive use in the $19^{\text {th }}$ century but the "Piedmonts" attribute is incorrect because their real location has much wider geographical boundaries.

This eighteenth-century practice must be sought in different ways and times. Only this example shows the vastness of the theme and the uncertainty of relationships. Currently, there is only one heterogeneous picture spread over time and space that needs a repertoire model suitable for containing the infinite variables. From the beginning, in fact, the final aim is to concentrate every action of the process - from detection to redesign - towards an information model containing a series of transmissible data, as accurate as possible.

The need is not only to not lose the complexity of the data but also to make this complexity as accessible as possible to an external user who wants to approach these issues. The use of BIM platforms could be the solution for creating a library with these features.

\section{A short overview of data integration and HBIM models}

Authors can include illustrations related to the accompanying text. It is the responsibility of authors to insert figures, graphics and images in the right place.

\subsection{Introduction to HBIM}

The introduction of BIM (Building Information Model) in the sector of AEC (Architecture, Engineering, Construction) is intended to integrate different types of information and allow collaboration and exchange of shared 3D models and structured data attached to them. This logic of data organization in one cohesive platform aims to allow collaboration between the architectural and construction fields. Updated heritage documentation techniques are the result of the increasing use of HBIM models for the management and digitization of cultural heritage assets (Dore, \& Murphy, 2017). Nowadays, HBIM models are overcoming the role of emerging practice, turning into a widespread process in constant growth, supported by new survey technologies and digitization practices that allow the reconstruction of parametric models (Banfi, Chow, Reina Ortiz, Ouimet, \& Fai, 2018). The complexity of cultural heritage entails the adoption of new solutions to support data storage and visualization and system management to avoid the loss of information between different models and projects. However, in most cases, due to different software interoperability or projects set up for different purposes, a traditional approach persists and generally, the information does not intersect correctly. The risk is that individual studies stay unconnected, depriving them of a potential historical connection, in time and space, which instead, if inserted in a shared platform, would get added evidential value. This study moves from the general idea of a geospatial database, integrating HBIM and GIS to promote and allow a broader dialogue between similar objects. That said, the still unexplored topic of brick vaults and their construction helps to identify the priority issues for a shared catalogue. The HBIM informative models can be accessed as HBIM libraries, as in the case of the product catalogue in the construction industry, or as Open Access format, to create an inventory model made by the built HBIMs coming from the punctual diverse case studies, and using them to feed a geographic database (GeoDB) (Brumana et al., 2018b).

\subsection{Data Integration and Interoperability}

The continuous evolution of BIM emerging software and its application in the cultural heritage leads to limitations about data transferring such as loss of information or incorrect translation. The use of a HBIM approach for modelling historical architectures/features introduces several further issues related to geometry complexity, level of detail, data organization, structural components classification and consequently new limits for a data exchange purpose.

It has to be said that, when we talk about BIM, defined as a semantically enriched model for knowledge, a growing and still ongoing issue concerns the creation of a catalogue of data and its consequent exchange between different platforms. If HBIM models, by themselves, can be considered a visual library and a solution for managing and storing information coming from different sources, including tangible and intangible data, multiple geometric information, photogrammetry and laser scanning measurements assimilated as different datasets (Chow \& Fai, 2017). However, it is necessary to understand how they can be properly integrated in the one inventory platform that overcomes that individual case-study with a view to a geospatial database. Information-sharing indeed should allow different inventory models to talk to each other.

\subsection{HBIM and geo-spatial DB}

The review of the recent literature evidences different tests to export HBIM models structure into GIS environment. Most of them show different applications to explore the limits due to interoperability issues between architectural and structural models and to overcome the gaps between the complexity of a heritage model and the software collaboration.

The main issue is how to transfer the logic of an objectbased software into the GIS database, considering data conversion and different kinds of information at different Levels of Details. The interoperability performance is hindered by inadequate communication between two different datasets, designed for different scaled objects. If GIS includes four types of Level of Detail (LOD), starting from the landscape scale, the more detailed one never reaches the complexity of BIM models. So as to make communication possible, it is necessary to identify what kind of semantic and geometry can be imported into a geospatial platform (Arroyo et al., 2017). All this is not about how to manage the geometry itself, but the data 
related to it, such as shared and family parameters, geographical coordinates and different Level of Information (LOI). BIM approach differs from the GIS approach because 3D data maintain their threedimensional output without being flattened to a vector image or a raster (Reina et al., 2019). Recently to closest studies (Matrone, Colucci, De Ruvo, Lingua, \& Spanò, 2019; Vacca, Quaquero, Pili, \& Brandolini, 2018) suggested two similar workflows visualise 3D objects into an Open Source GIS software where different architectural elements, modelled at a LOD300, successfully populate the DB where geometries and attributes are connected to each other.

\section{HBIM for vaulted systems}

\subsection{The evolution of the modelling workflow}

The BIM standards are insufficient for developing a parametric model that follows the complexity and deformation of a historical building that presents irregularities due to the movement of the structures, to inaccuracies or adjustments during the construction phase, but also to geometries that are too complex to be returned by just one software.
The virtual reconstruction of historical elements requires a modelling methodology (Fig. 1) that avoids arbitrary preselection of information and an excessive simplification of the shape (Oreni, Brumana, Georgopoulos, \& Cuca, 2014).

The methodology establishes guidelines to define correct LOD and LOA (Brumana, Banfi, Cantini, Previtali, \& Della Torre, 2019) and correct geometry interpretation. For this reason, it is essential to interact simultaneously with different modelling software, each one with a specific task to perform, defining a workflow that starts from slicing the point cloud (Autocad), to the reconstruction of surfaces (Rhinoceros) and finally to the creation of parametric solids (Revit). Therefore, the surfaces are imported into the BIM software and then it's possible to use a tool for generating three-dimensional elements from surfaces maintaining their complexity (Chow et al., 2019).

The case of the vaults (Fig. 2) falls into that category of elements that are too complex geometrically to be managed only by the BIM program. The survey of these structures shows that all of them are off by a few inches from the ideal geometrical vision of Architecture.

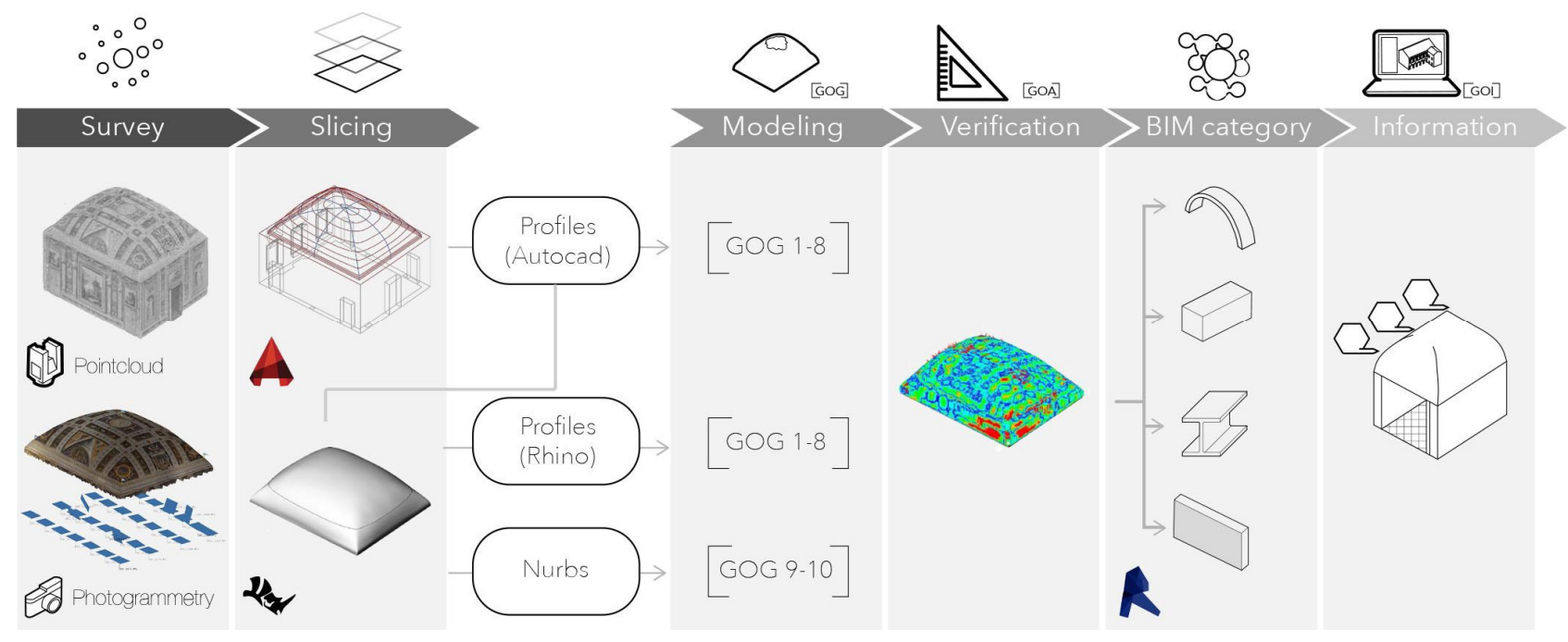

Figure 1: The vaulted systems are modelled following a dynamic interpretative workflow to avoid arbitrary preselection of information and geometry simplification.

The challenge focuses on a modelling practice to get a complex geometry in Revit and the definition of an accurate result in terms of geometrical deviations/anomalies. Different Level of Detail, Geometry and Information, acquired in Cremona palaces, provide an example when dealing with adaptive components. Considering vertical and horizontal sections cannot be used as generative profiles for all the vaults, because they are not enough to extrapolate the information needed, the translation of survey points into linear dimensional parameters within a family can drive the geometry.

Survey points and spring points in the case of springer vaults for example. Vault modelling, however, does not consist only in the generation of the main volume of the vault's body itself, but it is necessary to add all those elements that contribute to the formation of the complex structure. Reinforcement arches, frenelli, tie rods are all elements that cannot be ignored, and which therefore must be rebuilt digitally. These elements do not find a modern consideration and the BIM software is not able to generate them automatically, but it will be necessary to proceed through alternative ways by associating these structures, as done with vaults body, with categories that allow their modelling and assignment of the information that can characterize them.

The first step toward the definition of an HBIM library of vaulted systems toward a shared DB can be summarized in the definition of macro-families (ceiling, slabs, floors) and sub-components (as adaptive ones: structural, no structural elements, decorative layers). Finally, the geometry is related to a historical phase in Revit and its constructive technique and material. 


\subsection{Palazzo Magio Grasselli: a rich abacus of solutions}

Palazzo Magio has a great deal of heterogeneous information (Fig. 3) attributed to it deriving from years of analysis (Landi, 2011) aimed at the restoration that is affecting it. The organization of these data not only leads to correct their management such as to avoid data loss, but through the use of a coherent archiving method, new awareness can arise.

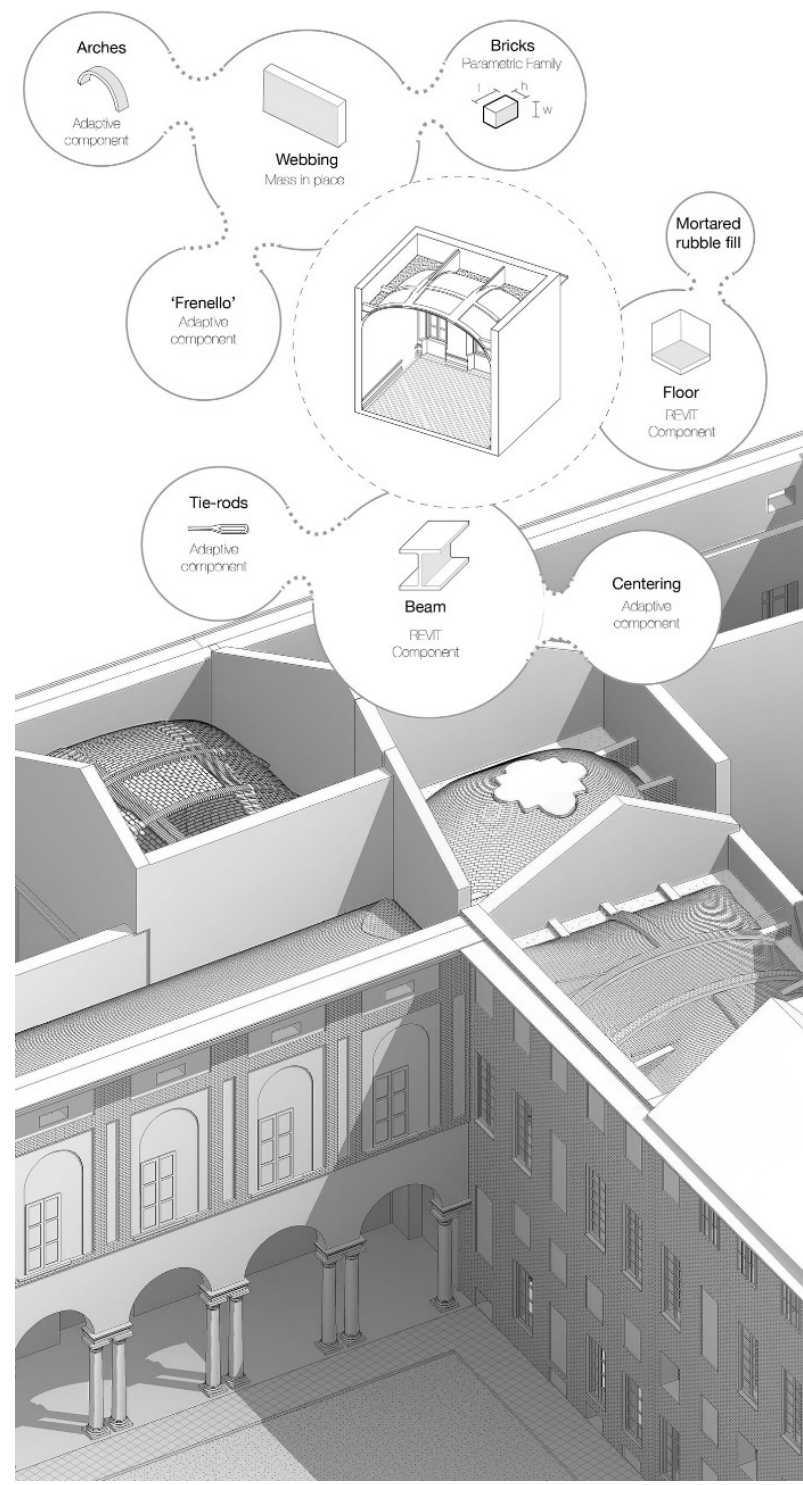

Figure 2: The HBIM of Palazzo Magio Grasselli. Highlighted are the main brick vaults built between the XVII and the XVIII centuries. The modelling process provides for the definition of macro-elements (Revit families) and sub-elements as adaptive components (structural, no structural elements, decorative layers).

The HBIM model of the palace is a valuable tool to store the data coming from the survey and archival sources within the modelled elements.

The knowledge of these elements, however, reaches a further degree of development when the information concerning the single units of the system is associated with it. If the solid model of the vault is able to define its real thickness, this will not be enough if the bricks are fundamental to understand how the vault was built.

To achieve this, the BIM model of the three main vaults of the building is integrated through the three-dimensional modelling of the previously reconstructed texture. The modelling, in this case, is quite heavy due to the numerous limitations provided by the software standards, related to the absence of specific families for complex elements and difficulty in reading the modelled elements.

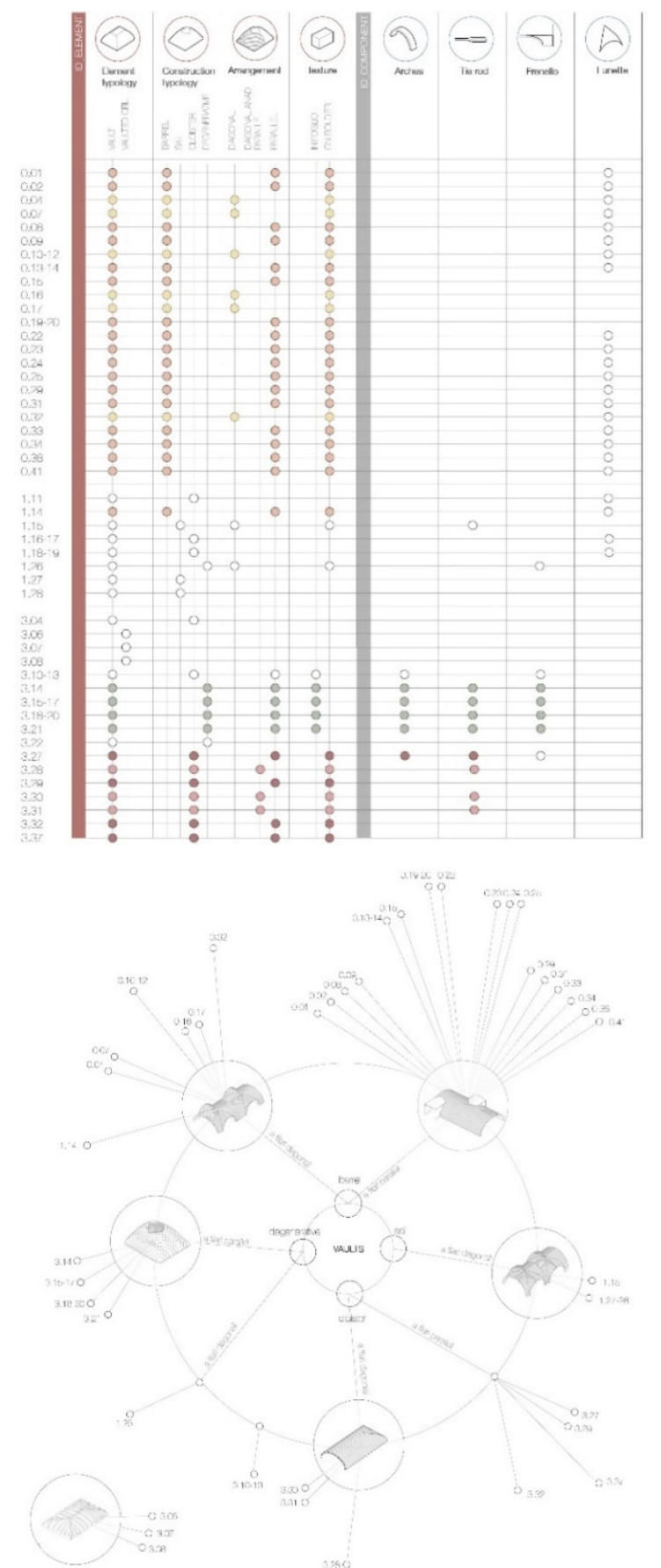

Figure 3: The classification of the vaults is the first step toward the definition of a HBIM targeted library.

This occurs through the creation of the single brick as an external family subsequently inserted within the main project and positioned individually on the surface of the vault. 
Moreover, according to the workflow, it is necessary to create specific families not only for the type of brick considered, but also for the face they show along with the ceiling. The type of family that best allows the modelling of the overall vault and in general, most complex heritage elements, is the metric generic model.

However, the HBIM environment can be considered an inventory model but not a complete database due to limitations of the software itself which can be summarized in two fundamental points: 1). lack of the possibility of subordination of the objects and of the aggregation of the individual objects to contribute to the formation of a complex object; 2). lack of adequate categories for some elements found in the historical building, which entails the adaptation of these objects into partially improper categories which lead to irregularities in the assignment of new data fields.

\section{Towards the genesis of a database}

In order to build a database aimed to accomplish the purpose for what has been conceived, it's necessary to organize sequentially the actions for the data collection and elements analysis.

The Road Map summarizes the main phases of the workflow starting from the identification of the case study, which involves the context where the same building is placed.

The preliminary actions concern the collection of data correlating two methods, the bibliographic research for the recovery of historical information and the digital survey through the use of emerging available techniques.

The information is subsequently analysed and linked to a three-dimensional BIM model. The role of the catalogue comes ex post, at the end of the analysis and synthesis of the work, turning into a tool for managing the model and the collected data (Fig. 4).

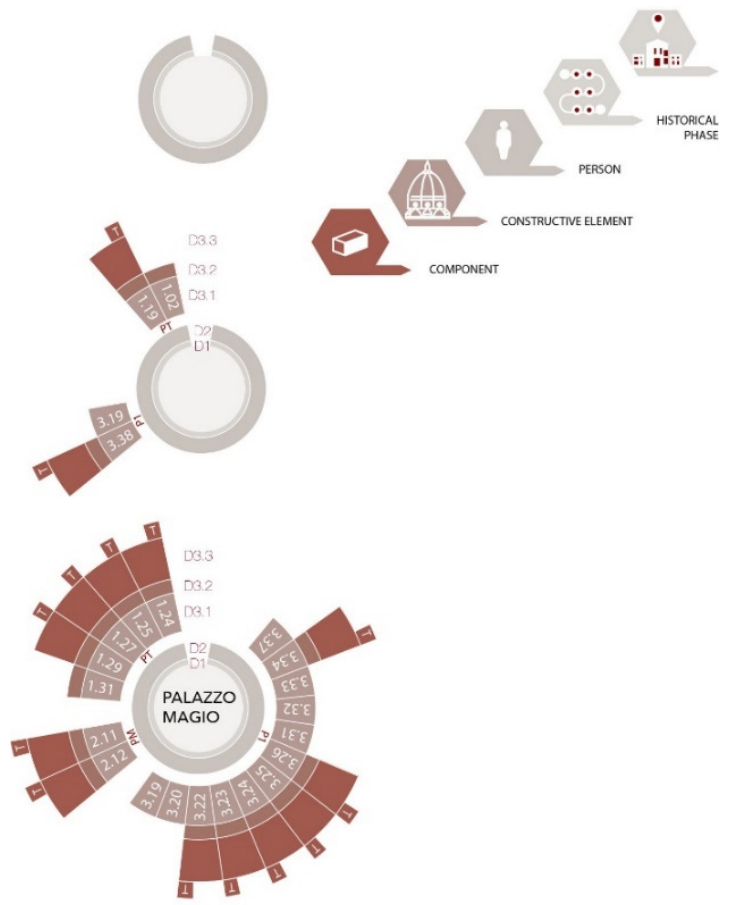

Figure 4: The generation of a shared DB gathering vaults containing different LOD.
Therefore, to avoid the system malfunction, first of all, indications are provided for each entry in the database so that it is easy to read for anyone, a sort of vocabulary, and at a later time, for those who, in addition to the consultation, wish to make changes or insert data to the database, a sort of filter element that checks every information before its insertion.

Clearly, it cannot be expected that any information included in the catalogue is the result of strong analysis. The feedback tool allows users to keep control of data that is not supported by a high level of knowledge and confirmed by strong sources.

The generation of the catalogue coincides with the need to re-order and establish a hierarchy within the data. In order to be functional, an open-access database must allow the population of new data by different users while preserving its linearity, doing so data integration won't involve modifications to the structure.

Given that the case study of Palazzo Magio contains, in addition to the presence of the BIM model, a considerable amount of information as a result of different survey techniques, the difficulty lies in not limiting the cataloguing to the types of vaults found in this building.

Taking into account the question of how to build a database and how can be feed with the collected data, there is a noticeable lack of information related to many aspects: the scarcity of historical documents regarding the vaults elements, the spread of stereotomic knowledge, the workers and their specific way of building, but also the absence of a study that collects all the possible bibliographic documentation, clearly extended outside Cremona, mapping all possible buildings.

Considering that this kind of work cannot lead to a result of absolute completeness, it is decided to overturn the reasoning.

We, therefore, abandon the idea of an inventory that adopts the logic of the greatest possible bibliographic extension by exploiting every single information present in the books and inserting all the indications of a certain type of physical context.

The approach chosen is to set up a construction model that develops an optimal form, a sort of matrix, accepting the incompleteness of the information collected and considering that even non-datable cases can re-enter it. We then proceed to the construction of a correct "matrix form" on Palazzo Magio (Fig. 5), being the case we are dealing with using the greatest accuracy. The genesis of this database is made by populating it with any reliable information by leaving the non-completable fields empty, understanding if these "gaps" are lack of information or more conceptual, which should therefore be fixed in the Magio starting box. For this reason, the precision of setting the starting form is essential to ensure that the insertion of one case does not continually call into question the previous one. It is not necessary for the database to extend infinitely, since the goal as previously stated, is not to create an extensive inventory, however at the same time we can't accept an arbitrary data insertion, based on the randomness of an extraneous bibliography. 

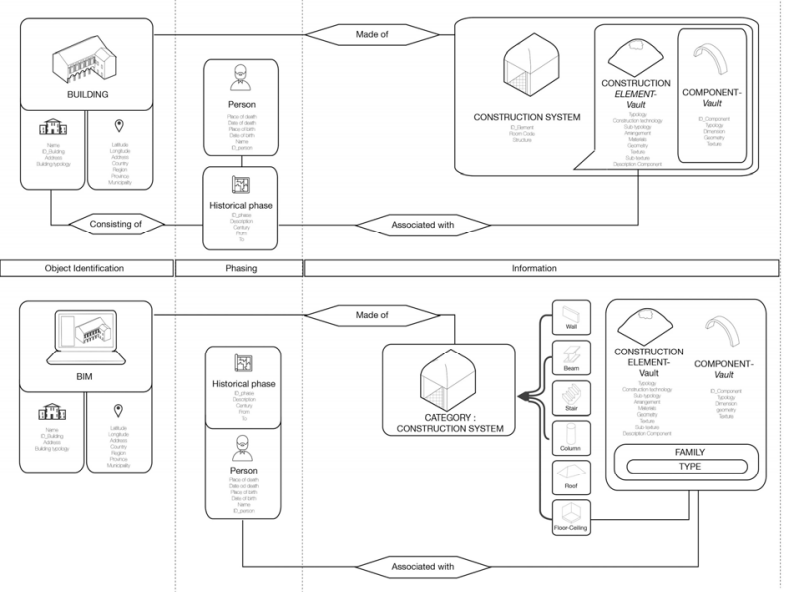

Figure 5: Logical model of the database vs. BIM library.

\section{Conclusion}

The model of Palazzo Magio is the result of a mapping process from a diverse set of remotely sensed survey data to generate a geometric framework that combines a digital model and a data information system. The generation of a highly accurate comprehensive digital model was supported by the point cloud and photogrammetry as primary sources and by archival documents as well as hand measurements taken on site for cross-referencing.

To sum up, it is necessary to understand how to make the database interact with the BIM model by overcoming limits due to data integration and modelling standards. The connection between the main geospatial inventory model and BIM libraries can take place through some precautions in setting up the creation of new information fields.

Following the logic of a bottom-up process, the database has a hierarchical structure in which every single component contributes to the reconstruction of an entire construction system, placing itself in a geographic (Fig. 6) context for knowledge dissemination.

If within a single platform one can proceed in a relatively serene manner, this does not happen if one has to imagine interoperability with other software with which connections have yet to be invented.

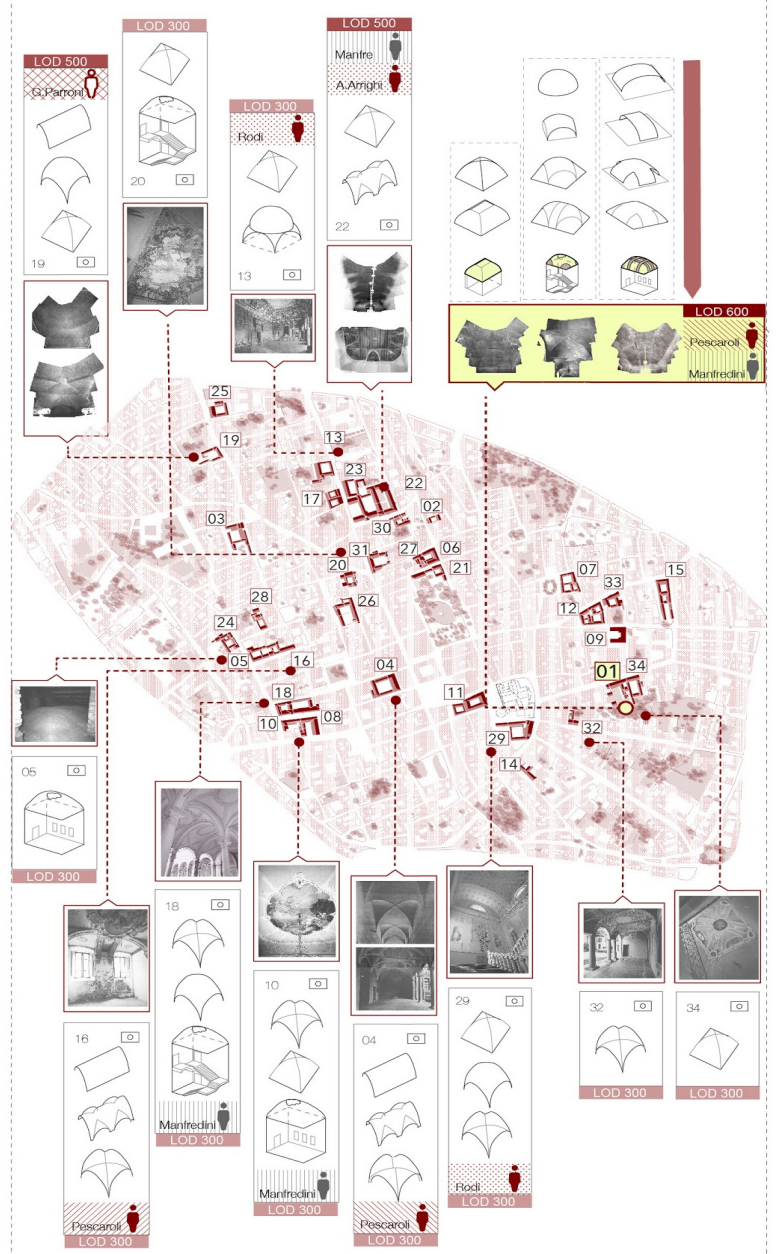

Figure 6: Mapping of main vaulted systems and their related information in Cremona.

\section{Acknowledgements}

The authors would like to thank Professors Raffaella Brumana and Fabrizio Banfi for the opportunity to explore a different modelling approach and to publish this punctual research following the latest studies on this topic in collaboration with the Gicarus Lab (DABC) at Polytechnic of Milan.

\section{References}

Arroyo Ohori, K., Biljecki, F., Diakité, A., Krijnen, T., Ledoux, H., \& Stoter, J. (2017). Towards an integration of GIS and BIM Data: what are the geometric and topological issues?. ISPRS Ann. Photogramm. Remote Sens. Spatial Inf. Sci., IV-4/W5, 1-8. https://doi.org/10.5194/isprs-annals-IV-4-W5-1-2017

Banfi, F., Chow, L., Reina Ortiz, M., Ouimet, C., \& Fai, S. (2018). Building Information Modeling for Cultural Heritage: The Management of Generative Process for Complex Historical Buildings. In: loannides M. (eds) Digital Cultural Heritage. Lecture Notes in Computer Science, 10605. Springer, Cham. https://doi.org/10.1007/978-3-319-75826-8_10

Brumana, R., Condoleo, P., Grimoldi, A., Banfi, F., Landi, A. G., \& Previtali, M. (2018a). HR LOD based HBIM to detect influences on geometry and shape by stereotomic construction techniques of brick vaults. Applied Geomatics, Special Issue GEORES2017. Geomatics and Restoration: Conservation of Cultural Heritage in the Digital Era. https://doi.org/10.1007/s12518-018-0209-3

Brumana, R., Condoleo, P., Grimoldi, A., Landi, A. G., Attico, D., Turrina, A., Banfi, F., \& Previtali, M. (2018b). HBIM Feeding Open Access Vault Inventory Through GeoDB HUB. In: Ioannides M. et al. (eds) Digital Heritage. Progress in Cultural Heritage: Documentation, Preservation, and Protection. EuroMed 2018. Lecture Notes in Computer Science, 11196. Springer, Cham. https://doi.org/10.1007/978-3-030-01762-0_3 
Brumana, R., Banfi, F., Cantini, L., Previtali, M., \& Della Torre, S. (2019). HBIM Level Of Detail - geometry - accuracy and survey analysis for architectural preservation. Int. Arch. Photogramm. Remote Sens. Spatial Inf. Sci. XLII-2/W11, 293-299. https://doi.org/10.5194/isprs-archives-XLII-2-W11-293-2019

Chow, L., \& Fai, S. (2017). Developing verification systems for building information models of heritage buildings with heterogeneous datasets. Int. Arch. Photogramm. Remote Sens. Spatial Inf. Sci., 42, $125-128$. https://doi.org/10.5194/isprs-archives-XLII-2-W5-125-2017

Chow, L., Graham, K., Grunt, T., Gallant, M., Rafeiro, J., \& Fai, S. (2019). The evolution of modelling practices on Canada's Parliament Hill: an analysis of three significant heritage building information models (HBIM). Int. Arch. Photogramm. Remote Sens. Spatial Inf. Sci. XLII-2N111, 419-426. https://doi.org/10.5194/isprs-archives-XLII-2-W11-419-2019

Dore, C., \& Murphy, M. (2017). Current State of the Art Historic Building Information Modelling. In International Archives of the Photogrammetry, Remote Sensing and Spatial Information Sciences - ISPRS Archives, 42, $185-92$. https://doi.org/10.5194/isprs-archives-XLII-2-W5-185-2017

Landi, A. G. (2011). Patrizi, notabili, costruzione della città. Fabbrica e tutela di palazzo Magio Grasselli a Cremona, 243.

Matrone, F., Colucci, E., De Ruvo, V., Lingua, A., \& Spanò, A. (2019). HBIM in a semantic 3d gis database. Int. Arch. Photogramm. Remote Sens. Spatial Inf. Sci. XLII-2/W11, 857-865. https://doi.org/10.5194/isprs-archives-XLII-2W11-857-2019

Oreni, D., Brumana, R., Georgopoulos, A., \& Cuca, B. (2014). HBIM library objects for conservation and management of built heritage. International Journal of Heritage in the Digital Era, 3(2), 321-334. https://doi.org/10.1260/20474970.3.2.32

Palacios Gonzalo, J. C. (1990). Trazas y cortes de cantería en el Renacimiento español. Ministerio de cultura, Instituto de conservacion y restauracion de bienes culturales, Madrid.

Pérouse de Montclos, J. M. (2000). Philibert De l'Orme architecte du roi (1514-1570). Paris, Mengè.

Piccoli, E. (2001). Le strutture voltate nell'architettura civile a Torino, 1660-1720. In: Dardanello, G. (ed.) Sperimentare l'architettura. Guarini, Juvarra, Alfieri, Borra e Vittone, pp. 38-96. Fondazione CRT, Torino.

Reina Ortiz, M., Yang, C., Weigert, A., Dhanda, A., Min, A., Gyi, M., Su, S., Fai, S., \& Santana Quintero, M. (2019). Integrating heterogeneous datasets in HBIM of decorated surfaces. Int. Arch. Photogramm. Remote Sens. Spatial Inf. Sci. XLII-2/W15, 981-988. https://doi.org/10.5194/isprs-archives-XLII-2-W15-981-2019

Vacca, G., Quaquero, E., Pili, D., \& Brandolini, M. (2018). GIS-HBIM integration for the management of historical buildings. Int. Arch. Photogramm. Remote Sens. Spatial Inf. Sci. XLII-2,1129-1135. https://doi.org/10.5194/isprs-archives-XLII2-1129-2018

Willis, R. (1842). On the construction of the vaults of the middle ages. Transactions of the Royal Institute of British Architects, 1(2), 1-61. Longman, Brown, Green and Longmans, London. 